\section{Biologists take degrading route to tackle cancer}

Alison Abbott, Munich

Not content with genomes and proteomes, biologists have added another '-ome' to

their lexicon: the degradome. Its

proponents say that it signals a fresh approach to cancer research. And the European Commission seems to agree on 15 June it awarded one of the largestever grants for life-sciences to a four-year project based on the concept.

The degradome encompasses all of the enzymes in the body that degrade proteins. There are about 560 such enzymes, called proteases, in humans. Many of them modify the environment of human tissues and contain their growth - making sure a liver stays liver-shaped, for example.

The range and levels of proteases expressed by a tissue change dramatically if it becomes cancerous. For example, normal tissue cells are fixed in position by a matrix. But cancer cells seek to break this down using certain proteases, so that they can escape into the blood stream and establish themselves in different tissues. Other proteases are marshalled to help build the blood vessels needed to feed growing tumours.

But therapeutic approaches based on disrupting such protease activity have so far been unsuccessful in clinical trials. Dylan Edwards, a cancer biochemist at the University of East Anglia in Norwich, $\mathrm{UK}$, and coordinator of the $€ 10.4$ million (US\$12.6-million) project, says that this is because the drugs tried have been designed to inhibit as many proteases as possible.

"Dogma has insisted that protease action must be blocked in as broad a manner as possible in cancer," says Edwards. "But we now know that the web of proteases is complex. Some of them inhibit, rather than facilitate, cancer growth." So researchers in the European project plan to investigate the biology of proteases and then design specific inhibitors to block them individually.

Involving 41 scientists from 13 countries, the project will cut across many different disciplines. It will depend initially on two mouse models - for breast and prostate cancer - later expanding to include colorectal and skin cancers. Biologists will study the expression of proteases to untangle which protease does what in normal and diseased tissues. The chemists in the team will work on developing highly selective inhibitors for diagnostics and therapeutics.

www.cancerdegradome.org

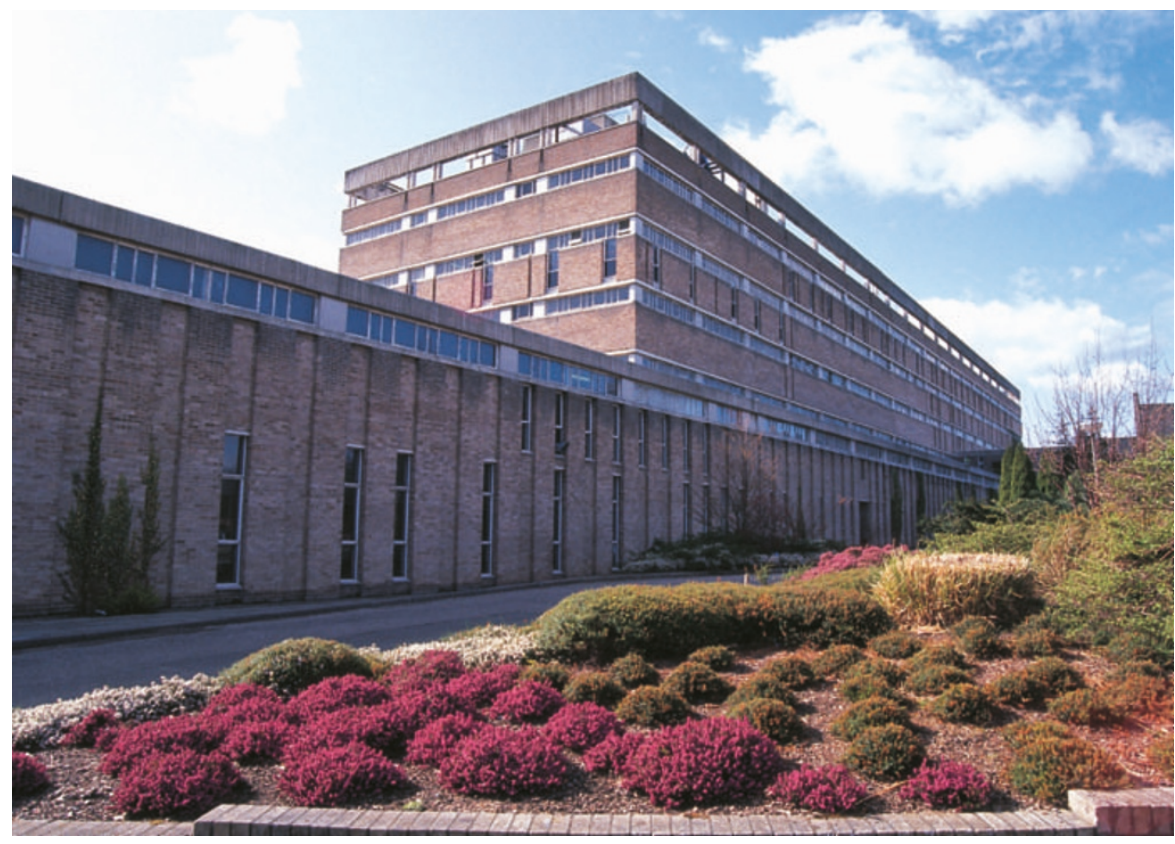

Physicists at Edinburgh's James Clerk Maxwell building will forge alliances with Scottish colleagues.

\title{
Scots propose SUPA plan for united approach to physics
}

Jim Giles, London

Scotland's top physicists are planning to band together to create a single national physics department. Advocates say that the plan will help them to compete with the world's élite research institutions

Under the scheme, which is part of a wider discussion about pooling resources across Scottish science, the country's six highest-rated physics departments will function as a single unit - the Scottish Universities Physics Alliance (SUPA). Members would remain in their individual universities but would bid for big grants together and offer joint graduate courses. Undergraduate teaching would remain outside the collaboration.

"This will brand Scottish physics with a strong identity," says Alan Miller, the viceprincipal for research at the University of St Andrews, which is a partner in SUPA. "We want to compete with Oxford, Cambridge and even the Massachusetts Institute of Technology and Harvard."

The idea, which will be considered by the Scottish Higher Education Funding Council on 25 June, would involve the creation of about 12 new positions at St Andrews and the other SUPA universities - Glasgow, Edinburgh, Heriot-Watt, Strathclyde and Paisley.

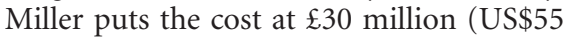
million) over five years, but says that it would pay for itself in the long-term by generating extra research income.

Some universities are likely to take leading roles in certain subjects, says Miller. For example, Glasgow and St Andrews have strengths in particle physics and materials, respectively. But he rules out the possibility of closing down groups or moving researchers to a single physics building at one site.

The move reflects changes in England, where, for example, the University of Manchester and UMIST (the University of Manchester Institute of Science and Technology) are merging to create a stronger, single institution, due to open in October. Officials at University College London and Imperial College London flirted with a merger idea in 2002, before backing down in the face of staff protests (see Nature 420, 350; 2002). In both cases, the need to become more globally competitive was the driver for change.

The trend may also be repeated in other subjects in Scotland. On the east coast, the chemistry departments at the universities of Edinburgh and St Andrews are considering merging their research and graduate teaching functions. A similar unit may be formed in the west of the country by the chemistry departments at Glasgow and Strathclyde.

"We'd welcome this," says Sean McWhinnie, science-policy manager at the Royal Society of Chemistry in London. "In Manchester, the merger will produce a world-class chemistry department. The same would apply in Scotland.”

Council officials say that it is too early to judge whether the approach should be applied more widely, but add that they are discussing the possibility with regard to biomedical research and the Earth sciences. 